\title{
Waste to Energy (WTE) Initiatives and Application of Frontier Technologies for Disaster Management in Coastal Andhra
}

\author{
A K Mittal, A. Chitra Devi, R V Ramarao
}

\begin{abstract}
Growing population, increased urbanization rates and economic growth are dramatically changing the landscape of domestic solid waste in terms of generation rates, waste composition and treatment technologies.The socio-economic structure of the Indian society makes per capita generation of waste much low compared to that of the western societies. A substantial amount of $M S W$ is recycled and reused through the primary intervention of rag pickers and second-hand markets, though there are problems like the health hazard to the rag pickers and the degradation and devaluation of the recyclables. This paper presents in brief an over view of the Municipal Solid Waste Management system which is the critical element towards sustainable metropolitan development and comprises segregation, storage, collection, relocation, processing and disposal of solid waste to minimize the adverse impacts on Environment. The recent attempts to increase the appreciation from $3 R$ to $5 R$ are also briefly dealt with in the case studies of three major towns in the coastal Andhra like Eluru, Kakinada and Visakhapatnam. The paper seeks to draw attention towards role of WTE technologies integration for disaster mitigation as part of sustainable development process.
\end{abstract}

Key Words: Waste to Energy (WTE), Municipal Solid Waste (MSW), Climate Change, Waste Composition and Treatment Technologies, Disaster Management.

\section{INTRODUCTION}

Growing population, increased urbanization rate and economic growth are dramatically changing the landscape of domestic solid waste in terms of generation rates, waste composition and treatment technologies. The global Municipal Solid Waste (MSW) generated is expected to grow faster than urbanization rates in the coming decades, reaching 2.2 billion tons/year by 2025 and 4.2 billion by 2050 (Hoornweg \& Bhada, 2012). ${ }^{1}$

According to World Bank Group (Waste Generation Urban Development, 2009) ${ }^{2}$, MSW generation rates are influenced by economic development, the degree of industrialisation, public habits, and local climate. As a general trend, the higher the economic development, the higher the amount of MSW generated. Urban India is facing an ever increasing challenge of providing for the incremental infrastructural needs of a

Revised Manuscript Received on Octobery 22, 2019

A.K.Mittal, Research Scholar, School of Managem,ent Studies, Sathyabama Institute of Science and Technology, Chennai. Email: mits35@yahoo.com

Dr.A. Chitra Devi, Research Supervisor, Associate Professor, School of Management Studies, Sathyabama Institute of Scince and Technology, Chennai. Email: chitrapeter06@gmail.com.

Dr. R.V Ramarao, Joint Supervisor, Institute of Development and policy Studies, Visakhapatnam. Email: rvrra040@gmail.com growing urban population. According to the 2011 census, the population of India was 1.21 billion; of this $31 \%$ live in cities. It is further projected that by 2050 half of India's population will live in cities (Ali \& Dkhar, 2018). ${ }^{3}$ With this increasing population, management of Municipal Solid Waste (MSW) in the country has emerged as a severe problem not only because of the environmental and aesthetic concerns but also because of the sheer quantities generated every day. According to Central Pollution Control Board (CPCB) 1,27,486 TPD (Tons per day) of MSW was generated in India, with an average waste generation of $0.11 \mathrm{~kg} /$ capita/day. Of the total waste generated, approximately 89,334 TPD (70\%) of MSW is collected and only $15,881 \mathrm{TPD}(12.45 \%)$ was processed or treated. Segregation at source, collection, transportation, treatment and scientific disposal of waste was largely insufficient leading to degradation of the environment and poor quality of life.The socio-economic structure of the Indian society makes per capita generation of waste much low compared to that of the western societies. A substantial amount of MSW is recycled and reused through the primary intervention of rag pickers and second-hand markets, though there are problems like the health hazard to the rag pickers and the degradation and devaluation of the recyclables (Joshi \& Ahmed, 2016). ${ }^{4}$

\section{A. Categorisation of $M S W$}

The current definition and category as per the Solid Waste Management Rules 2016 in India are as follows - a) Solid Waste, B) Hazardous Waste, C) Biomedical Waste, D) Electronic Waste, E) Construction \& Demolition Waste, F) Plastic Wastes \& Biomedical Waste, D) Electronic Waste, E) Construction \& Demolition Waste, F) Plastic Wastes and G) Lead Acid Batteries. The Solid Waste Management Rules, 2016 have further classified the solid wastes into different categories which include biodegradable waste, dry waste, non-biodegradable waste, combustible waste, domestic hazardous waste, residual solid waste and sanitary waste.

\section{TECHNOLOGIES}

WtE technologies can be applied to several types of waste: from the semi-solid (e.g. thickened sludge from effluent treatment plants) to liquid (e.g. domestic sewage) and gaseous (e.g. refinery gases) waste. The current most known $\mathrm{WtE}$ technology for MSW processing is incineration in a Combined Heat \& Power (CHP) plant.

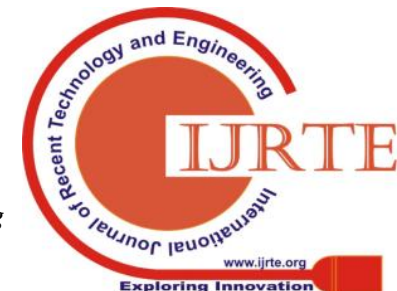




\section{Coastal Andhra}

According to the World Energy Resources ${ }^{5}$, with proper MSW management and the right control of its polluting effects on the environment and climate change, MSW has the opportunity to become a precious resource and fuel for the urban sustainable energy mix in the future.There is a need to use geographically designed and based thematic layers such as land use, land cover, geology, geomorphology, soil type, slope characteristics, and features located in the study area to make right decision using Multi-Criterion Decision Support Analysis (MCDA). GIS provide economic and feasible information to identify and map the locations, output of which is used for locating of best site suit of disposal of waste. Remote sensing technology may be utilised for development of various GIS outputs.

\section{A. Recycling}

Recycling includes the collection, sorting, marketing, and processing of materials removed from the solid waste stream and transformation or remanufacture of those materials for use as feedstock for new products and/or other productive uses. Successful recycling includes an examination of the solid waste stream to determine what is recyclable and marketable. Recycling efforts can be implemented in the residential, commercial and industrial sectors.Recycling, in concert with other methods of integrated municipal solid waste management (IMSWM), including reduction, reuse, composting, energy recovery, and land filling provides for the safe handling of municipal solid waste (Allen, 2014) ${ }^{6}$.

\section{ENERGY BALANCE FOR NEW TECHNOLOGIES}

Energy balance for new technologies is an essential factor in selection of a technology. The requirement is briefly mentioned covering various technologies e.g. Biomethanation, Biogas, Incineration, Pyrolosis, Plasma, Gasification \& Polymer to Fuel Process and such others.

According to the MoUD, Swatch Bharat Guide Book ${ }^{7}$, Energy in the form of heat or electricity is obtained from waste if there is enough energy in the waste in the first place to take care of plant operations and leave a surplus. That is why Energy Balance to calculate 'Energy In and Out' is important before selecting a particular technology.

For wet waste, in bio-methanation no moisture needs to be evaporated out of it and pumping energy consumption is minimal. The biogas produced can be directly used for cooking in the kitchen that produced the wet waste, with no deduction of energy required for transport.EAI website ${ }^{8}$ states that the Production of electricity from biogas engines attains $40 \%$ efficiency at best and so it is not a technically preferred option. Direct incineration of wet waste has been banned by National Green Tribunal (NGT) because it takes a huge amount of external energy to evaporate its initial moisture content, dry, shred convey and burn it to produce steam and then convert steam calorific energy into electrical energy with current maximum $25 \%$ efficiency only. So no surplus energy is available from it, rather the reverse.

\section{LIMITATIONS \& CHALLENGES}

An increasingly demanding set of Environmental, Economic \& Technical factors represents a challenge to the development of these technologies. In fact, although WtE technologies using MSW as feed are nowadays well developed, the inconsistency of the composition of MSW, the complexity of the design of the treatment facilities, and the air-polluting emissions still represent open issues for this technology.In Biomethanation, wet biodegradable waste is required; for Combustion of RDF, dry high organic waste is required; for Gasification, organic or fossil based carbonaceous material is required; and for Pyrolysis, organic waste is required. Mass Burning of MSW is the only method which does not require any segregation of waste and uses mixed waste. However, this method of Mass Burning is detrimental to the environment and not be resorted to on a mass scale. Most of the above mentioned technologies require proper segregation of waste. Lack of an efficient mechanism to segregate waste into biodegradable/dry/wet/ carbonaceous materials/ components is still to be established.

\section{A. MSW \& Climate Change}

Swachh Bharat Mission Municipal Solid Waste Management Manual (2016) ${ }^{9}$ brought out various aspects related to Climate Change, gender equity aspects and informal sector integration in MSW). MSW is related to climate change in several ways: ISWM reduces the emissions of greenhouse gases (mainly carbon dioxide and methane). Waste minimization, waste recycling, $\mathrm{WtE}$ strategies and landfill gas capture and use are reduction strategies for greenhouse gases, either directly (landfill gas capture) or by better utilising the energy and resources inherent in products and materials (climate footprint).MSW should also reflect needs for adaptation to future impacts of climate change. An example is site selection and design of landfills, which might have to reflect changing ground water tables or patterns of rainfall.

\section{B. Gender Equity Aspects}

Women are involved in and affected by MSW in multiple ways. They work in Urban Local Bodies (ULB, e.g. many street sweepers and door step collectors are also women/ children) and also in the informal sector. They are disproportionally affected by inadequate and unhygienic practices in MSWM. This requires interventions which would protect women from the harmful effects of unhygienic practices which also affect their social functions in child care and family food supply. Moreover, they are often the first customers of any MSW collection service and engage in segregation of waste at source at the household level. The SWM system design should therefore consider the health and safety concerns of women. The SWM system should also engage in a social impact assessment which allows for gender gaps to be brought to the forefront for systematic analysis and corrective/ appropriate responses.

\section{Informal Sector Integration in MSW}

An implication of the comprehensive understanding of ISWM is that it will involve various stakeholders - going far beyond a merely public task for the ULB. Important groups include the private sector and the informal sector. The informal sector plays an important role in the SWM 
value chain by recovering valuable materials from waste. It includes both, "kabadi system / scrap dealers" and rag pickers. They help reducing environmental impacts by improving resource recovery and reducing waste quantities for disposal.

\section{MUNICIPAL SOLID WASTE MANAGEMENT (MSWM)}

The Municipal Solid Waste Management system is a critical element towards sustainable metropolitan development and comprises segregation, storage, collection, relocation, processing and disposal of solid waste to minimise the adverse impact on Environment. Otherwise, the MSW would become a factor for propagation of number of health problems to the urban population.SWM in the country is becoming better day by day, with the new and revised legislation of waste management in the year 2016, new schemes for cleanliness and waste management, namely Swachh Bharat Mission, AMRUT, Smart Cities, JNNURM etc. to tackle the challenges of rapid urbanization, population growth and unplanned development in many cities. Emphasis on technology and PPP mode are given to enhance resource recovery and deriving energy and nutrients. The thrust in waste management in new legislation is to minimize the quantum of waste by adopting the "Concept of 5-R"-Reduce, Reuse, Recover, Recycle and Remanufacture through integrated waste Management. The ultimate objective is zero waste to landfills with the core objectives of reduction in contamination to soil, water and air, minimization of adverse impacts on environment and health, increasing the level of resource recovery and recycling to reduce the Greenhouse Gas emissions (Ghosh, 2017). ${ }^{10}$ After implementation of the Swachh Bharat Mission (SBM), significant improvement has taken place in the status of compost plants. The five states having highest number of functional /sub optimal compost plants as in July 2017 are, Karnataka (23), Maharashtra (17), Andhra Pradesh (15), Gujarat (12) and Tamil Nadu (10). $\left(\right.$ Ghosh, 2017) ${ }^{11}$

\section{POLICY TRENDS - 3RS \& WASTE MANAGEMENT AREA (FUTURE)}

Waste generation in Indian cities will increase five-fold to touch 260 million tonnes per year by the year 2047 (TERI, 2014). The recent Rules pertaining to different categories of wastes management put great emphasis on waste minimization and $3 \mathrm{Rs}$ promotion. The proposed strategies include:

- Defining the roles and responsibilities of various stakeholders and putting in place an operating framework.

- Greater emphasis on civic engagement by involving public and NGOs.

- Establishing Institutional mechanism at State Level for planning, technical, financial and implementation support.

- Promoting public private partnership (PPP) investments for developing treatment and final disposal facilities on Regional level on cluster based approach (Ghosh, 2017). ${ }^{12}$

Environment friendly operation, cost effectiveness and accessibility to the local community are important factors to achieve efficient systems. Case studies which have been undertaken of three major towns in the coastal Andhra like Eluru, Kakinada and Visakhapatnam provide the limitations and challenges faced by the local urban development bodies in providing sustainable environment duly taking in to considerations the type of municipal solid waste to be treated and its disposal.

\section{IMPORTANCE OF WASTE MANAGEMENT / WTE TECHNOLOGIES IN DISASTER MANAGEMENT}

Anthropogenic causes including construction have direct impact on environment and climate change leading to higher rate of disaster occurrence. WTE plays a significant role in keeping the environment safe and clean in normal times and at the same time development of resources / techniques for futuristic use, including post disaster recovery phase. Adhoc/unmanaged waste leads to escalation of disaster apart from hindrance to the recovery and rescue efforts. Post disaster, huge volume of various waste (both hazardous and non hazardous: chemical, biological, infrastructure, natural/ plant based) could lead to health, safety and environmental risk while slowing down the recovery efforts. Rightful waste management utilising WTE frontier technologies remains foremost important, for mitigation both prior to and after disaster.

WTE resources availability could be a catalyst for speedy recovery and reconstruction phase of Disaster Management. Long term Plans for DRR includes reduction of vulnerability, capacity development and optimum management utilising technology. For a green and sustainable environment and development, authorities should consider reducing adverse environment impact by relevant policies for dual use of WTE along with resource list compilation.

\section{ACKNOWLEDGEMENTS}

The authors duly acknowledge the technical advice given in preparation of this paper from Dr.Sasiprabha, Pro-VC, Satyabama University, Chennai and Shri S.Satyanarayana, Former Chief Engineer and Chairman, IDPS, Visakhapatnam for his valuable comments.

\section{REFERENCES}

1. Daniel Hoornweg and Perinaz Bhada - (March 2012), "What a Waste- A Global Review of Solid Waste Management", No. 15P9.

2. World Bank Group - (2009), "Waste Generation Urban Development Series - Knowledge Papers"- P3.

3. Qazi Syed Wamiq Ali \& Nathaniel B Dkhar - (Dec 2018),India's Rampant Urban Water Issues And Challenges (TERI website).

4. Rajkumar Joshi \& Sirajuddin Ahmed - (2016), "Status and Challenges of Municipal Solid Waste Management in India" Cogent Environmental Science 2: 1139434 (http://dx.doi.org/10.1080/23311843.2016.1139434)

5. World Energy Resources - (2013), Waste to Energy World Energy Council, Strategic Insight,P2)

6. Richard Allen (International Secretary) (Jan, 2014), "Swana 
Waste to Energy (WTE) Initiatives and Application of Frontier Technologies for Disaster Management in

\section{Coastal Andhra}

Technical Policy T-6.1 Municipal Solid Waste Recycling", (https://community.swana.org/HigherLogic/ System).

7. MoUD, GoI- (2016), Swatch Bharat Guide Book : "A Step-By-Step Manual To Change our Habits and Clean our Habitats" (P20,21),

8. Energy Alternatives India (EAI)- Website http://www.eai.in/ref/ae/wte/mor/gas_engines.html).Home Page.

9. MoUD - Central Public Health and Environmental Engineering Organisation (CPHEEO) - 2016, Swachh Bharat Mission Municipal Solid Waste Management Manual - P 42.

10. Prof. Dr. Sadhan Kumar Ghosh, United Nation Centre for Regional Development (UNCRD) - (Nov 2017), "State of the 3Rs in Asia And The Pacific, the republic of India"

http://www.uncrd.or.jp/content/documents/5688[1121]\%20India.pdf - P13.

11. Prof. Dr. Sadhan Kumar Ghosh (UNCRD) - (Nov 2017), "State of the 3Rs in Asia and the Pacific, the republic of India" -P20/21.

12. Prof. Dr. Sadhan Kumar Ghosh (UNCRD) - (Nov 2017), "State of the 3Rs in Asia and the Pacific, the republic of India" -P24. and Ministry of Environment.He guided the R\&D programmes of various Ministries and Planning Commission in respect of waste land classification, GIS based Natural Resource Data Management System, Environmental Statistical Information system, Eco conservancy of coastal lake systems and such others. He retired as the Principal of Andhra University Engineering College, Visakhapatnam, Andhra Pradesh. He guided 20 candidates for $\mathrm{Ph} . \mathrm{D}$., over 200 research publications and over 12 International Country reports and over 200 consultancy projects.Presently he is involved in major Advisory works through projects for the Ministry of Defence, GOI (Indian Navy). He is also the coordinator for the Forum for Action Research and Policy Analysis (FARPA) involved in discussing state level policy issues and to focus on initiating policy guidelines.

\section{AUTHORS PROFILE}

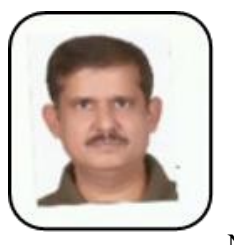

A K Mittal is presently working as a commissioned officer in the Indian Navy and is pursuing his research

in " Mitigation and Risk Reduction Strategies of Natural Disasters- with case studies from North

Sathyabama Institute of Science and Technology ( deemded to be University), Chennai. He was founding member of an Expert Appraisal committee (EAC) of Ministry of Environment and Forest. He presented a paper on "Mitigation \& Adaptation in Energy Environment Interface" at a round table national level conference (Championing Energy Business towards a life friendly planet "organized by NTPC School of Business under agies of IIT (Ahmadabad) in Dec 18. He also participated in a five day national level workshop on "Disaster Risk Reduction and Resilience" by National institute of Disaster Management, New Delhi in Apr 19.

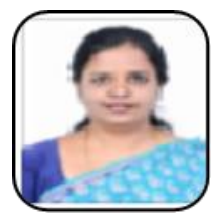

Dr.A.Chitra Devi, MBA, M. Phil, PhD joined Sathyabama Institute of Science and Technology as Lecturer in 2002, and is presently working as Associate professor. She is also active member in the Centre for Academic Partnership and International Relations Department in the institution which aims in building international collaborations with Academic Institution ,Industries and Research Organisations all over the world to facilitate Faculty and Students Exchange Programs. She has completed Ph.D in Work Life Balance from Sathyabama Institute of Science and Technology in 2014, Present areas of Research Interest include Human Resource Management .She has PhD: Work Life balance, completed year 2014 from Sathyabama Institute of Science and Technology, MBA from University of Madras and UGC- NET qualified in the year December 2012. Her Research Interests includes Industrial \& labour relations, Work life balance, Training \& Development and Human resource development. She has over 20 Publication in various national and international journals and is examiner / paper setter in University of Madras, AMET University, SRM University and MOP Vaishnav College for Women (Autonomous).

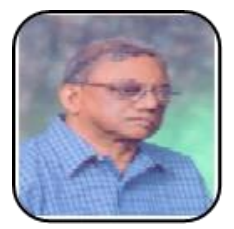

Prof. R V Rama Rao is presently the Director of the Institute of Development and Policy Studies (IDPS), Visakhapatnam. He has served on a number of high level committees of Govt. of India and as a member of the Advisory committee on JNNURM of the Prime Minister. He was a recipient of a National level Award for the work on Climate Change. He was one of the project directors of the International programme on Climate Change and with specific attention to sea level rise all along the coastal zone of Andhra Pradesh. He prepared the first draft of the state of Environment Report for the country and his most significant major contribution has been the preparation of compendium volume on the deep sea fans of Bay of Bengal for the Department of Science and Technology. He was also coordinator of the first Wasteland classification developed for the Planning Commission 